\section{DATA MODEL DESCRIPTION FOR THE DESCARTES AND CIDER CODES}

\section{Hanford Environmental Dose \\ Reconstruction Project}

T. B. Milley

S. J. Ouderkdrk

W. E. Nichols

P. W. Eslinger

\title{
DISCLAIMER
}

This report was prepared as an account of work sponsored by an agency of the United States Government. Neither the United States Government nor any agency thereof, nor any of their employees, makes any warranty, express or implied, or assumes any legal liability or responsibility for the accuracy, completeness, or usefulness of any information, apparatus, product, or process disclosed, or represents that its use would not infringe privately owned rights. Reference herein to any specific commercial product, process, or service by trade name, trademark, manufacturer, or otherwise does not necessarily constitute or imply its endorsement, recommendation, or favoring 0 ; the United States Government or any agency thereof. The views and opinions of authors expressed herein do not necessarily state or reflect those of the United States Government or any agency thereof.

January 1993

Letter Report prepared for the Technical Steering Panel and the Centers for Disease Control under Contract 200-92-0503(CDC)/18620(BNW)

\section{Battelle}

Pacific Northwest Laboratories

Richland, Washington 99352

\section{MASTEn}




\section{PREFACE}

The primary objective of the Hanford Environmental Dose Reconstruction (HEDR) Project is to estimate the radiation dose that individuals could have received as a result of emissions since 1944 from the U.S. Department of Energy's (DOE) Hanford Site near Richland. Washington. An independent Technical Steering Panel (TSP) directs the project which is conducted by Battelle Pacific Northwest Laboratories (BNW).

One of the major objectives of the HEDR Project is to develop several computer codes to model the airborne releases, transport and environmental accumulation of radionuclides resulting from Hanford operations from 1944 through 1972. In July 1992, the HEDR Project Manager determined that the computer codes being developed (DESCARTES, calculation of environmental accumulation from airborne releases, and CIDER, dose calculations from environmental accumulation) were not sufficient to create accurate models.

A team of HEDR staff members developed a plan to assure that computer codes would meet HEDR Project goals. The plan consists of five tasks: 1) code requirements definition, 2) scoping studies, 3) design specifications, 4) benchmarking, and 5) data modeling. This report deiines the data requirements for the DESCARTES and CIDER codes.

The work documented in this report was performed concurrently with the other tasks. Information developed in the course of the work for this document influenced the course of other scoping studies and vice versa. In the interest of prompt interaction between the HEDR staff, the TSP, and the public, this report is being issued in its current form. 


\section{GLOSSARY}

age

animal media

animal type

CIDER

creamery

data unit size (bytes)

days

deminimus dose level

DESCARTES

feed type

feeding regime
Seven ages are defined: pre-natal, 0-1 year, 1-3 years, 3-7.5 years, 7.5-12.5 years, 12.5-17.5 years, and 17.5+ years.

Animal products for which radionuclide concentrations will be estimated. The requirements document states that the computer code must handle up to 12 animal media. Eleven have been currently defined: goat milk, grocery milk rural, grocery milk urban, creamery milk, feeding regime 1 , feeding regime 2 , feeding regime 3 , feeding regime 4, eggs, beef, poultry

Animal species and dietary groupings for which radionuclide concentrations will be estimated. The following are current defined: cattle, chicken, dairy cow, ariủ goat

Calculation of Individual Doses from Environmental Radionucildes (computer code)

A milk processing and distribution center. There are currently 26 creameries defined for the area under study.

Byte size of both integers and reals on the HEDR Sun 690 Computer. The data unit size is 4 bytes.

Maximum number of days covered by the study. The number of days is 10,251 , dertved from 28 years (19451972) $x 366$ days/year to account for leap years +31 days to account for the one month. December, in 1944 for which there is data.

Radionuclide concentration below which there are no measurable health effects

Dynamic EStimates of Concentrations and Accumulated Radionuclides in Terrestrial EnvironmentS (computer code)

Plant media which are part of an animal's diet . Currently, ftve plant media have been defined: grain, alfalfa, pasture, sllage, grass hay.

Pre-defined dietary composition representative of cow diets. Four have currently been defined. 
feeding season

foods

irrigated nodes

lifestyle

months

nodes

organs

pathways

plant media

radionuclides

RATLHET
Perlod of annual dietary intake of cows. The intake currently has 5 periods ciefined: winter, spring, summer, early fall, late fall.

Nine human-consumed foods are defined: beef, leafy vegetables, other vegetables, fruit, grain, poultry, eggs, fresh inilk, stored milk.

Those nodes which are irrigated and could support a commercial dairy or commercial vegetabie production. Currently 200 nodes out of the 2091 nodes are considered to have been irrigated during the period of this study.

Two lifestyles are defined: urban and rural.

Maximum number of months covered by the study. The number of months is 337 , dertved from 28 years (19451972) $\times 12$ months/year + 1 month to account for the one monch. December, in 1944 for which there is data.

Multiple rectangular areas that have been created by a division of the geographic area under study. Currently there are 2091 nodes defined. Both DESCARTES and CIDER computer codes will perform calculations on a node basis.

Human body organs for which doses are calculated. Currently 4 organs are defined: thyroid, red-bone marrow, lower large intestine, and. for calculation purposes, a factor used to estimate effective dose.

The route by which radionuclides provide dose to the human body. Currently 10 pathways are defined:

external, inhalation, beef, leafy vegetable, other vegetable, fruit, grain, poultry, eggs, and milk.

Vegetation for which radionuclide concentrations will be estimated. The requirements document states that the computer code must handle up to a maxdmum of 15 plant media. Lleven have been currently defined: inner leafy, outer leafy, other vegetables, inner fruit, outer fruit, grain. alfalfa, pasture, grass hay, silage, sagebrush.

Radioactive elements. For this study there are three radionuclides that appear to contribute dose: iodine-131. ruthenium-103, ruthenium- 106.

Regional Atmospheric Transport Code for Hanford Emissions Tracking (computer code) 
realizations $(R)$

resuspẽinded soll

seasons

$\operatorname{sex}$

stochastic

years
Random sample points on a stochastic curve that describe the data. For this study, we have assumed that 100 data points will adequately define any distribution.

Atrborne soll particles

Four seasons are defined: spring, summer, fall, whiter.

Two sexes are defined: male and female.

Pertains to a quantity that varies randomly and which is modeled by a statistical distribution

Maximum number of years, 29, covered by the study (19441972) 


\section{CONTENTS}

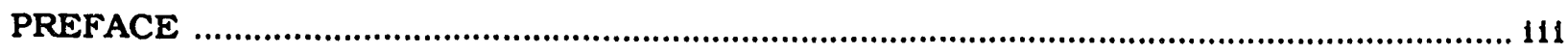

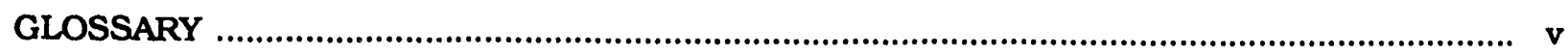

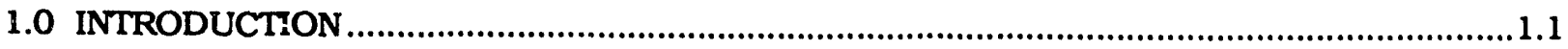

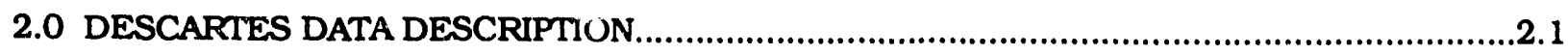

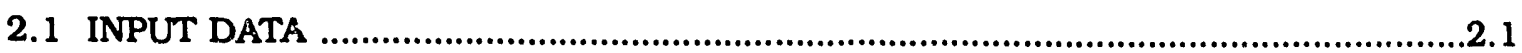

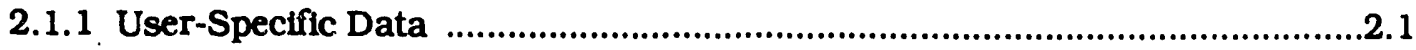

2.1.2 Air Concentration and Surface Deposition Data...................................2.1

2.1.3 Realization-Dependent Environmental Data ...........................................2.1

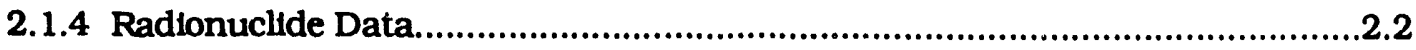

2.1.4.1 Constant Radionuclide Data .....................................................2.2

2.1.4.2 Stochastic Radionuclide Data ...................................................2.3

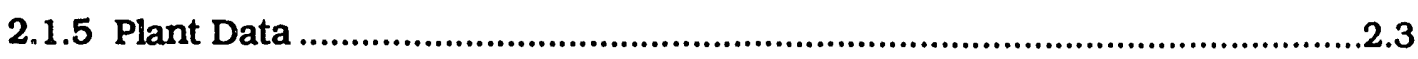

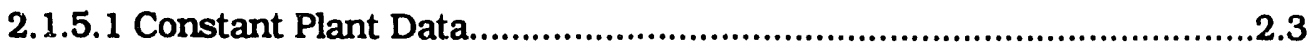

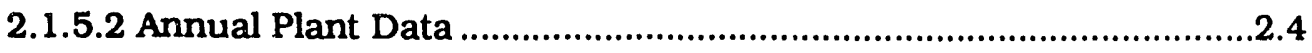

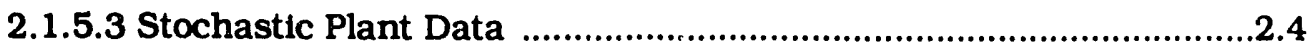

2.1.5.4 Radionuclide-Specific Plant Data ................................................2.5

2.1.5.5 Agricultural Practices Data .........................................................2.5

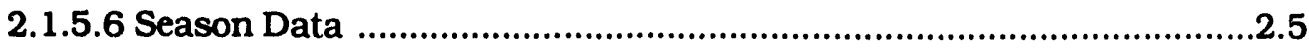

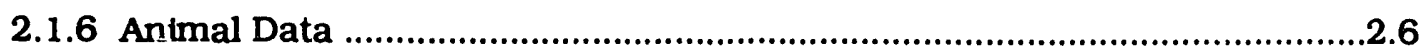

2.1.6.1 Animal Soll-Consumption Data................................................2.6

2.1.6.2 Animal Diet Data.....................................................................2.6

2.1.6.3 Feed Storage-Time Data .....................................................2.7

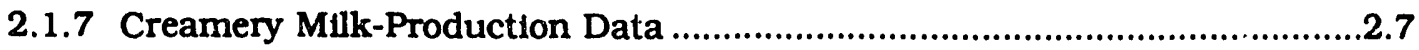

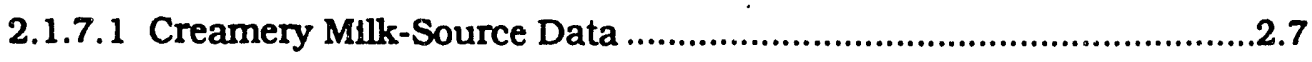

2.1.7.2 Commercial Cow Feeding-Regime Data ......................................2.8

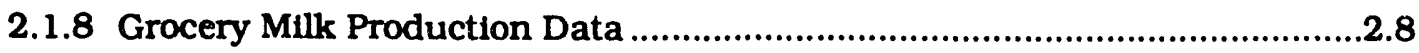

2.1.8.1 Rural Grocery Milk-Source Data...............................................2.8

2.1.8.2 Urban Grocery Milk-Source Data ...........................................2.9

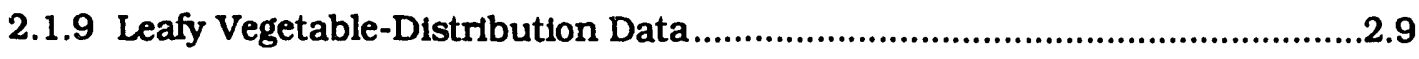

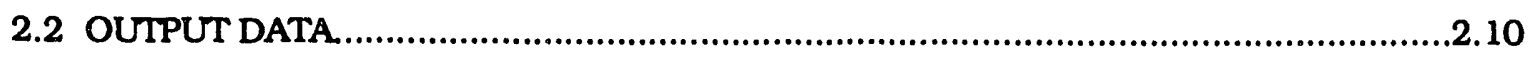

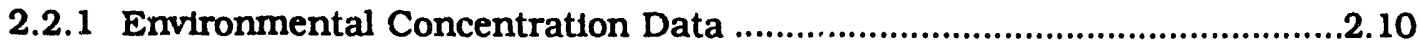

2.2.2 Creamery Concentration Data ...........................................................2.10

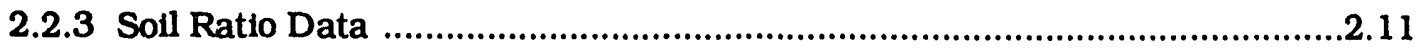

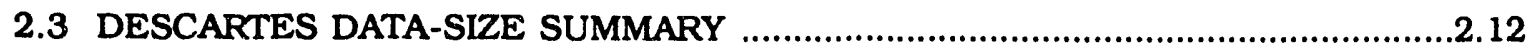




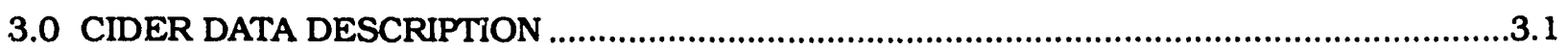

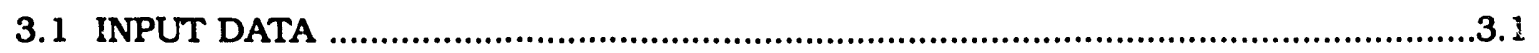

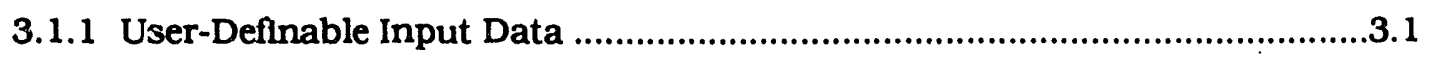

3.1.1.1 Code Run-Control Input Data............................................................

3.1.1.2 Indtvidual Input Data..................................................................1

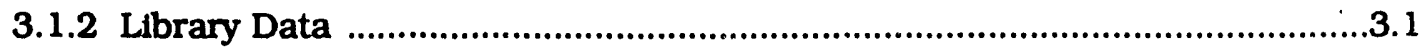

3.1.2.1 External Dose-Factor Library Data .............................................

3.1.2.2 Internal Dose-Factor Lubrary Data ..............................................2

3.1.2.3 Reference Diet Library Data ...........................................................

3.1.2.4 Reference Outdoor-Time Library Data .........................................3.3

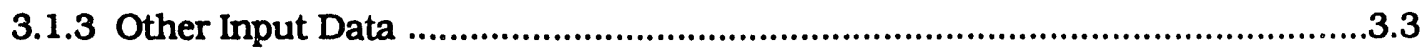

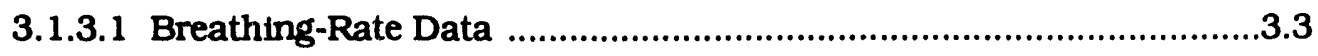

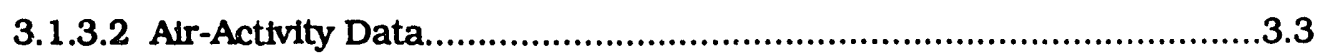

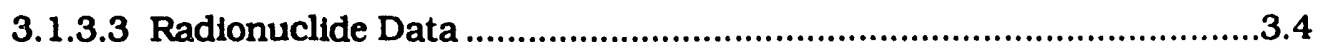

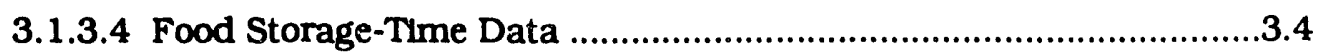

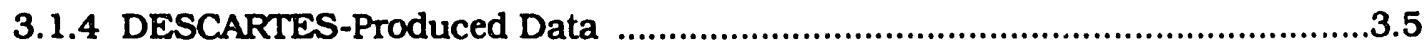

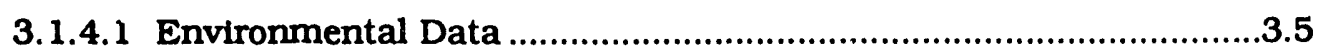

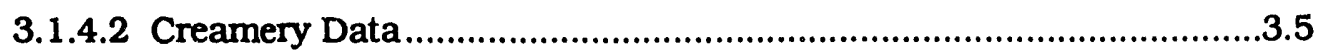

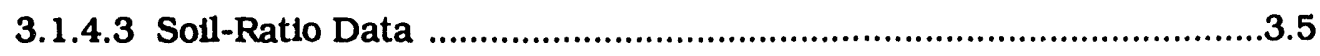

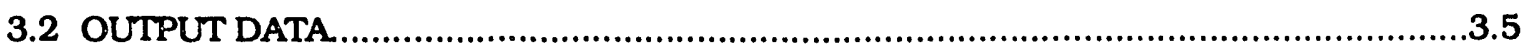

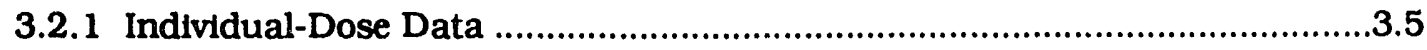

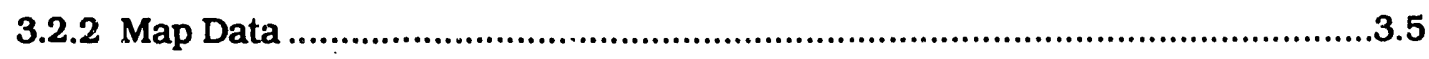

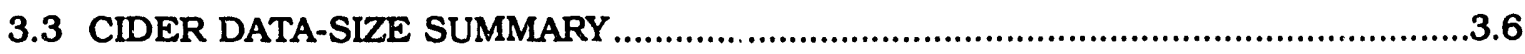

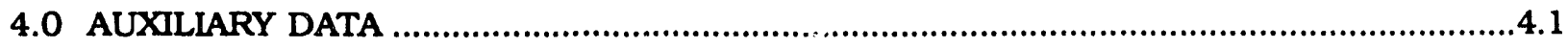

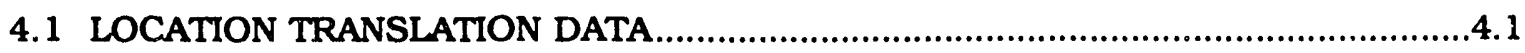

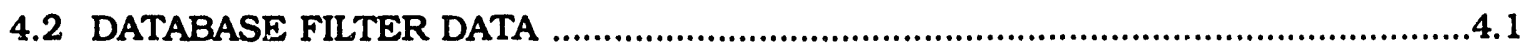

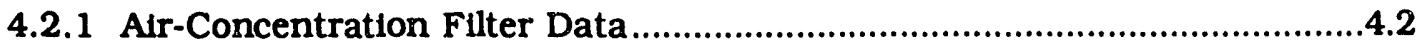

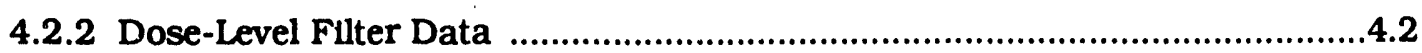

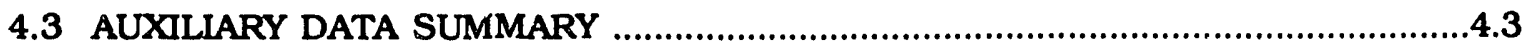

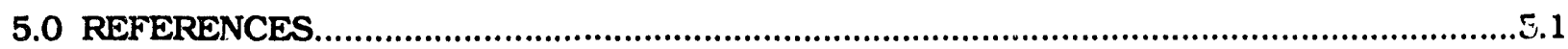




\subsection{INTRODUCTION}

The Hanford Environmental Dose Reconstruction (HEDR) Project is developing several computer codes to estimate doses from the release and transport of radionuclides through the atmosphere. Two of the computer codes being developed are DESCARTES and CIDER. The DESCARTES computer code will be used to estimate the concentration of radionuclides in environmental pathways from the output of the air transport code: RATCHET. The CIDER computer code will use information provided by DESCARTES to estimate the dose recelved by an individual.

This Data Model Description report is a working document that describes the data requirements for the DESCARTES and CIDER codes. The sources of the data are identifled and the flow of information within and between the codes discussed. All data necessary to produce close estimates from alrborne contaminants are identified.

This document is limited to a desmription of the data required by the DESCARTES and CIDER computer codes. It does not address code design issues or other topics covered by documents required by the HEDR Software Requirements Specification. This document is not intended to be a final product, and it will be updated as the parameters become fully defined.

The estimates on data size stated in this document assume a "worst case" scenario. In order to calisulate the dose of radiation a person may have received in any given location, the geographic area addressed by the HEDR Pruject ywll be divided into a grid. The grid suggested by the draft requirements contrins 2091 units called nodes. That is the grid size used in this document. However, a grid size of 1064 nodes is recommended to reduce the data size. The data size is directly related to the number of nodes used because both DESCARTES and CIDER perform calculations on a node basis.

Another aspect of the "worst case" scenario that has been assumed in this study is that the calculation time increment is daily/weekly. Using weekly/monthly data Instead would reduce the size requirements by approximately a factor of six.

The third aspect of the scenario included here is that three radionuclides (iodine-131. ruthenium-103, and ruthentum-106) will be estimated. Because lodine-131 was the largest contributor to the historical Hanford dose (Napier, 1991) and because of database size considerations, estimating only one radionuclide, lodine-131, is recommended.

A discussion of the data flow for the DESCARTES environmental accumulation code is discussed in Section 2, and the data flow for the CIDER code is discussed in Section 3. Section 4 
of this document describes the auxdliary data that are needed to manipulate the data into the appropriate forms required by the DESCARTES and CIDER codes. References are given in Section 5. 


\subsection{DESCARTES DATA DESCRIPTION}

\subsection{INPUT DATA}

Three types of data are necessary to run the environmental pathways model. DESCARTES: 1) user-specified, 2) radionuclide concentrations in air and upper soil (from the RATCHET code), and 3) realization-dependent environmental parameters produced from various tasks within the HEDR Project.

\subsubsection{User-Specified Data}

Some variables will be user-specified. The data size requirement for these variables is expected to be small. Specifications for these data will be supplied in the DESCARTES Software Design Description and the DESCAR TES User's Guide.

\subsubsection{Alr Concentration and Surface Deposition Data}

The data produced by the RATCHET code are the air concentration and surface deposition of radiation. RATCHET produces a set of 100 realizations for dally, time-integrated air concentration and swriace deposition of radiation for a 41 -node by 51-node grid. There is a set of 100 flles of dally wiformation (one for each realization) for each month of the period for which contaminant concentrations are being estimated. The air concentration and surface deposition data size is derived from the following:

Parameters

Dally time-integrated air concentration

Surface deposition

Dependencies

Radionuclides, nodes, days, realizations
Source

Output from RATCHET Output from RATCHET

\section{Data Size}

$51.4 \mathrm{~Gb} \quad(2$ parameters $\times 3$ radionuclides $\times 2091$ nodes $\times 10,251$ days $\times 100$ realizations $\times$ 4 bytes)

\subsubsection{Realization-Dependent Environmental Data}

Some environmental data vaiy only by realizat on and are independent of radionuclide. location, time, and plant or animal type. The realization-dependent environmental data size is derived from the following: 
Foliar interception $(\alpha)$ PNWD-2023 HEDR(a)

Weathering rate $\left(\lambda_{\text {weath }}\right)$ PNWD-2023 HEDR

Root zone soll density (rhorz) PNWD-2023 HEDR

Upper soll layer density (rhous 1 ) PNWD-2023 HEDR

Mass of particulates in a $\mathrm{m}^{3}$ of outdoor air (ML) PNWD-2023 HEDR

Deposition velocity of resuspension $\left(V_{d}\right)$ PNWD-2023 HEDR

\section{Dependencies}

Realization

\section{Data Size}

\section{$2.4 \mathrm{~Kb} \quad$ (6 parameters $\times 100$ realizations $\times 4$ bytes)}

\subsubsection{Radionuclide Data}

The DESCARTES computer code contains several parameters that are radionuclide specific. The data values for lodine-131 are contained in the PNWD-2023 HEDR document.. The values for any other radionuclides will have to be determined.

\subsubsection{Constant Radionuclide Data}

The only non-stochastic parameter for the radionuclide data is radiological decay. Radiological decay depends on the specific radionuclides. The constant radionuclide data size is dertved from the following:

Parameter Source

Radiological decay constant $\left(\lambda_{\text {rad }}\right)$ PNWD-2023 HEDR

\section{Dependencies}

Radionuclides

\section{Data Size}

12 bytes ( 1 parameter $\times 3$ radionuclides $\times 4$ bytes)

(a) The location for each of the references to PNWD-2023 HEDR are identified by the variable symbol; 1.e., ML is in the ML chapter. 


\subsubsection{Stochastic Radionuclide Data}

The following parameters will be modeled stochastically. The stochastic radionuclide data size is dertved from the following:

Parameters

Leach rate from root zone to deep soll $\left(\lambda_{\text {Leach }}\right)$

Percolation rate from upper soll to root zone $\left(\lambda_{\text {Perc }}\right)$

Rain splrsh rate constant $\left(\lambda_{\text {Splash }}\right)$

Concentration ratio (CR)

Transfer factor for beef $\left(\mathrm{TF}_{\text {beed }}\right)$

Transfer factor for eggs (TF eggs $_{\text {) }}$

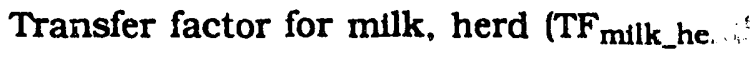

Transfer factor for milk, individual cow $\left(\mathrm{TF}_{\text {milk_ind }}\right)$

Transfer factor for poultry (TF poultry)

Dependencies

Radionuclide,(a) realizations

Data Size

\section{Source}

PNWD-2023 HEDR

PNWD-2023 HEDR

PNWD-2023 HEDR

PNWD-2023 HEDR

PNWD-2023 HEDR

PNWD-2023 HEDR

PNWD-2023 HEDR

PNWD-2023 HEDR

PNWD-2023 HEDR

$3.6 \mathrm{~Kb} \quad(9$ parameters $\times 1$ radionuclide $\times 100$ realizations $\times 4$ bytes)

\subsubsection{Plant Data}

The DESCARTES computer code contains several parameters that are plant specific. The requirements document states that the computer code must handle up to 15 plant media. Only 11 plant media have currently been defined.

\subsubsection{Constant Plant Data}

The constant plant data consist of parameters that depend only on the type of plant being considered. The constant plant data size is dertved from the following:

(a) For this data, only one radionuclide at a time needs to be in memory. 


\section{Parameters}

Minimum biomass $\left(B_{\min }(p)\right)$

PNWD-2023 HEDR

Plant growth rate constant $\left(k_{g}(p)\right)$

PNWD-2023 HEDR

Plant senescence aging rate constant $\left(k_{0}(p)\right)$

PNWD-2023 HEDR

\section{Dependenctes}

Plant media

\section{Datassize}

180 bytes ( 3 parameters $\times 15$ plant media $\times 4$ bytes)

\subsubsection{Annual Dlant Data}

Annual plant data refer to values of plant-specific factors that vary from year to year over a period of 29 years (1944-1972). These data will be modeled as siochastic. The annual plant data size is dertved frorn the following:

Earameters

Source

Maximum blomass $\left(B_{\max }(p, y r)\right)$ PNWD-2023 HEDR

Dependencles

Plant media, years, realizations

\section{Datasize}

$174 \mathrm{~Kb}$ (1 parameter $\times 15$ plant media $\times 29$ years $\times 100$ realizations $\times 4$ bytes)

\subsubsection{Stochastic Plant Data}

The stochastic plani data are dertved from the following:

\section{Parameters}

Source

Dry-weight to wet-weight converston factor $\left(f_{d}(p)\right)$ PNWD-2023 HEDR

Translocation factor from outer to inner vegetation $\left(f_{\text {trans }}(p)\right)$ PNWD-2023 HEDR

\section{Dependencies}

Realizations, plant media 


\section{Data Size}

$12 \mathrm{~Kb}$ (2 parameters $\times 100$ realizations $\times 15$ plant media $\times 4$ bytes)

\subsubsection{Radionuclide-Specific Plant Data}

The following plant data are stochastic and vary by radionuclide. The radionuclidespecific plant data stze is dertved from the following:

Parameters

Sounce

Food-processing loss fraction $\left(\mathrm{L}_{\text {proc }}(1, \mathrm{p})\right)$ PNWD-2023 HEDK

\section{Dependencies}

Radionuclides, plant media, realizations

\section{Data Size}

$18 \mathrm{~Kb}$ (1 parameter $\times 3$ radionuclides $\times 15$ plant media $\times 100$ realization $\times 4$ bytes)

\subsubsection{Agricultural Practices Data}

These data describe agricultural methods in the study area and will be used to determine the radionuclide concentrations on the date of consumption. The data will also be used to reset the biomass after appropriate biomass-affecting activities. For this set of data, plant type has been expanded to replace the single value of alfalfa with three values of alfalfa, representing the first, second, and third harvests. This gives us a total of 17 plant media. The agricultural practices data size is derived from the following:

Parameters

Date soil tilled (Till_date)

Date crop harvested (Harv_date)

Dependencies

Nodes, plant media, years, realizations

\section{Data Size}

$825 \mathrm{Mb}$ (2 parameters $\times 2091$ nodes $\times 17$ plant media x 29 years $\times$ 100 realizations $x 4$ bytes)

\subsubsection{Season Data}

These data describe the start and end dates for each of the cow feeding seasons that affect agricultural practices. The season dala size is derived from the following: 
Season start date (Season_beg)

Season end date (Season_end)

Task 06

\section{Dependencles}

Nodes, years, seasons, realizations

\section{Data Size}

$242.5 \mathrm{Mb} \quad(2$ parameters x 2091 nodes $\times 29$ years $\times 5$ seasons x 100 realizations $\times 4$ bytes)

\subsubsection{Animal Data}

These data are necessary to determine the radicnuclide concentration in animal products. The data given here describe animal consurnption and the storage times for feed products.

\subsubsection{Animal Soll-Consumption Data}

The animal soll consumption data give 100 estimates of the soil consumed by a given animal type. Soll consumption varies by animal type and by time on pasture. For this estimate, the four types of animals used are cattle, chickens, cows, and guats. Data for chickens and cows are gtven in the paramter document, PNWD-2023 HEDR. The values for the other types of animals will have to be determined. The animal soll-corisumption data size is dertved from the following:

\section{Parameters}

Soll-ingestion rate $\left(\mathrm{FS}_{\text {chicken }}\right.$ and $\left.\mathrm{FS}_{\text {cow }}\right)$

\section{Dependencies}

Animal media, realizations

\section{Data Size}

$1.6 \mathrm{~Kb}$ (1 parameter $\times 4$ animal media $\times 100$ realizations $\times 4$ bytes)

\subsubsection{Animal Diet Data}

The animal diet data gtve 100 estimates of the consumption rate of five types of feed in a given animal's diet. The animal diet data size is dertved from the following:

\section{.}


Mass of feed type consumed by an animal in a day $\left(\mathbf{R}_{v_{-}} \mathbf{a}\right)$

Dependencies

Animal types, feeding regimes, feed types, seasons, realizations

\section{Data Size}

$160 \mathrm{~Kb}$ (1 parameter $\times 4$ antmal types $\times 4$ feeding regimes $\times 5$ feed tyres $\times 5$ seasons $\times 100$ realizations $x 4$ bytes)

\subsubsection{Feed Storage-Time Data}

These data specify how long feed is stored before it is consumed by agricultural animals. These feed-spectic data will be modeled stochastically. The feed storage-time data size is derived from the following:

\section{Parameters}

Time between harvest and ingestion of stored feed by milk animals $\left(\mathrm{th}_{\mathbf{s}}(\mathrm{v})\right)$

\section{Source}

Task 06

\section{Dependencles}

Feed types, realizations

Data Size

$2 \mathrm{~Kb} \quad$ (1 parameter $\times 5$ feed types $\times 100$ realizations $\times 4$ bytes)

\subsubsection{Creamery Milk-Production Data}

There are two sets of data that are necessary to produce estimates of the radionuclide concentrations in milk at creameries: the radionuclide concentration of milk at its source and the data relating to the sources of milk for a creamery. The radionuclide concentration in milk from a given node is estimated by the four feeding regimes for cows.

\subsubsection{Creamery Milk-Source Data}

For each creamery, there is a list of those nodes that have provided milk. There are currently 26 creameries definded for this study. No more than 200 nodes provide milk for a given creamery. Total contributions from all sources must equal 100 percent. The creamery millk-source data size is derived from the following: 
Contribution of node to millk at creamery $(\operatorname{frac}(\mathrm{C}, \mathrm{N}))$

PNL-7227 HEDR

Dependencies

Irrigated nodes, creameries, realizations

Data Size

$2.08 \mathrm{Mb}$ (1 parameter $\times 200$ irrigated nodes $\times 26$ creameries $\times 100$ realizations $\times 4$ bytes)

\subsubsection{Commercial Cow Feeding-Rertme Data}

These data provide a set of 100 estimates of the fractional contributions of up to 4 feeding regimes for that node. Total contributions from all sources must equal 100 percent. The commerctal cow feeding-regime data size is dertved from the following:

Parameter

Source

Contribution of feeding regime to milk at node $(\mathrm{frac}(\mathrm{N}, \mathrm{r}))$

PNL-7227 HEDR

pependencies

Irrigated nodes, feeding regimes, realizations

Data Size

$320 \mathrm{~Kb}$ (1 parameter $\times 200$ irrigated nodes $\times 4$ feeding regimes $\times 100$ realizations $\times 4$ bytes)

\subsubsection{Grocery Milk Production Data}

Concentrations in both rural and urban grocery millk will be provided for those nodes in the commercial production/distribution area. The methods for calculating the concentrations in the two types of milk is the same, but different blends are allowed to reflect a difference in lifestyle.

\subsubsection{Rural Grocery Milk-Source Data}

The rural grocery milk-source data provide a means of establishing which creamerles provided milk to that grocery and the fraction of all milk provided by each creamery. Total contributions from all sources must equal 100 percent. The rural grocery milk-source data size is derived from the following:

Parameter

Contribution of creamery to rural grocery milk at node (frac(N,C))

\section{Source}

PNL-7227 HEDR 


\section{Dependencies}

Nodes, creameries, realizations

\section{Data Slze}

$21.74 \mathrm{Mb}$ (1 parameter $\times 2091$ nodes $\times 26$ creamerles $\times 100$ realizations $\times 4$ bytes)

\subsubsection{Urban Grocery Milk-Source Data}

The urban grocery milk-source data provide a means of establishing which creameries provided milk to that grocery and the quantity of milk provided by each creamery. Total contributions from all sources must equal 100 percent. The urban grocery milk-source data size is dertved from the following:

Parameter

Source

Contribution of creamery to urban grocery milk at PNL-7227 HEDR node $(\operatorname{frac}(\mathrm{N}, \mathrm{C}))$

\section{Dependencies}

Nodes, creameries, realizations

\section{Data Size}

$21.74 \mathrm{Mb}$ (1 parameter $\times 2091$ nodes $\times 26$ creameries $\times 100$ realizations $\times 4$ bytes)

\subsubsection{Leafy Vegetable-Distribution Data}

The leafy vegetable distribution data provide a fractional contribution from the $\mathbf{2 0 0}$ irrigated nodes where leafy vegetables could have been produced. The leafy vegetablesdistribution data size is dertved from the following:

\section{Parameter}

Source

Contribution of leafy vegetables from irrigated node to grocery $\left(\operatorname{frac}\left(\mathrm{N}_{\mathrm{r}}, \mathrm{N}_{\mathrm{g}}\right)\right)$

(PNWD-2022 HEDR)

\section{Dependencles}

Nodes, irrigated nodes , realizations

\section{Data Size}

$167.28 \mathrm{Mb}$ (1 parameter $\times 2091$ nodes $\times 200$ irrigated nodes $\times 100$ realization $\times 4$ bytes) 


\subsection{QUTPUT DATA}

Output from the DESCARTES computer code will be stored for interpretation and use in the CIDER dose estimation code.

\subsubsection{Environmental Concentration Data}

The environmental concentration data are the concentrations of radionuclides in all media. In this case, media are a combination of plant media (15 possible), animal media (12 possible), air (1 possible), upper soll (1 possible), and rost-zone soil (1 possible), totaling 30 media. These data will be written to a series of computer flles. This series of flles will be interpreted and filtered by a pre-processor to the CIDER code. The formula to determine the byte size required by the environmental cencentration data is dertved as follows:

\section{Parameter}

Environmental concentration (Conc)

Dependencies

Nodes, days, media, realizations

Data Size

$257.22 \mathrm{~Gb}$ (1 parameter $\times 2091$ nodes $\times 10,251$ days $\times 30$ media $\times 100$ realizations $\times 4$ bytes)
Source

Calculated in DESCARTES

\subsubsection{Creamery Concentration Data}

The creamery concentration data contain 100 estimates of the radionuclide concentration in milk produced at each of the creameries. These data are provided so that individuals ma pecify a creamery as their milk source rather than home-produced or grocery milk which is tied to their node of residence. The creamery concentration data size is derived from the following:

\section{Parameter}

Concentration of milk at creamery $(\operatorname{Conc}(C))$

Dependencies

Creameries, days, realizations

Data Size

$107 \mathrm{Mb} \quad$ (1 parameter $\times 26$ creamerles $\times 10,251$ days $\times 100$ realizations $\times 4$ bytes) 


\subsubsection{Soll Ratio Data}

The dose due to resuspended soll calculated in CIDER requires the ratio of two DESCARTES parameters, mass loading (ML) and density of the upper soll layer (rhousl). These data will be written to a computer flle containing 100 realizations of the ratio. The soll ratio nta size is dertved from the following:

\section{Parameter}

Ratio of soll parameters $\mathrm{ML} / \mathrm{rho}_{\mathrm{usl}}$

Dependencies

Nodes, realizations

Data Size

$836 \mathrm{~Kb}$ (1 parameter x 2091 nodes x 100 realizations $\times 4$ bytes)

\section{Source}

Calculated in DESCARTES 


\subsection{DESCARTES DATA-SIZE SUMMARY}

To compute the totals all numbers have been rounded off to the nearest full integer. Zero indicates those data requiring less than half a megabyte.

\section{Data Name}

Air and surface concentration

Realization dependent

Constant radionuclide

Stochastic radionuclide

Constant plant

Annual plant

Stochastic plant

Radionuclide specific plant

Agricultural practices

Season

Animal soll consumption

Animal diet

Stored feed holdup time

Creamery milk source

Commercial cow feeding regime

Rural grocery millk source

Urban grocery milk source

Leafy vegetable distribution

Environmental concentration

Creamery database

Soll ratio

Total
Data Size (Mb)

51400

0

0

0

0

0

0

0

825

243

0

0

0

2

0

22

22

167

257220

107

310,009 


\subsection{CIDER DATA DESCRIPTION}

\subsection{INPUT DATA}

Several types of data are required to run CIDER: user information describing specific individual pari meters, code run-control input, library data fles necessary for computing doses, and radionuclide concentration data frCm DESCARTES needed for the calculations.

\subsubsection{User-Definable Input Data}

The user musi supply a limited amount of control data to initiate a CIDER run. The user may also override the dietary and other parameters.

\subsubsection{Code Run-Control Input Data}

The code run-control input will be further defined in the CIDER Software Design Description and the CIDER User's Gulde.

\subsubsection{Individual Input Data}

The inilividual must supply certain parameters to provide CIDER with its initial setup. The user mav override various parameters describing diet, lifestyle, etc.

\subsubsection{Library Data}

It is necessary to have several library data files when using the CIDER computer code to calculate doses. Some of these data may be overridden by the individual.

\subsubsection{External Dose-Factor Library Data}

The external dose-factor library is a file consisting of 100 estimates of external dose conversion factors by organ and radionuclide. Currently, only factors for the effect of iodine131 on the thyroid are avallable in the external dose-factor library. The external dose-factor library data size is derived as follows:

Parameters

Immersion dose-rate factor $\left(\mathrm{DF}_{\mathrm{imm}}\right)$

Soll activity dose-conversion factor $\left(\mathrm{DF}_{\mathrm{rz}}\right)$

Plane deposition-dose factor ( $\mathrm{DF}_{\mathrm{us}}$ )

\section{Dependencies}

Radionuclides, organs, realizations
Source

PNWD-2023 HEDR

PNWD-2023 HEDR

PNWD-2023 HEDR 


\section{Data Size}

$14.4 \mathrm{~Kb}$ (3 parameters $\times 3$ radionuclides $\times 4$ organs $\times 100$ realizations $\times 4$ bytes)

\subsubsection{Internal Dose-Factor Library Data}

The internal dose-factor library is a flle consisting of 100 estimates of internal dose conversion factors by age, sex, organ and radionuclide. Currently, only factors for the effect of lodine-131 on the thyroid are avallable (see FNWD-2023 HEDR). The internal dose-factor library data size is derived as follows:

\section{Parameters}

Ingestion dose-conversion factor ( $\mathrm{DF}_{\text {ing }}$ )

Inhalation dose-conversion factor $\left(\mathrm{DF}_{\mathrm{Inh}}\right)$

Dependencles

Radionuclides, ages, sexes, organs, realizations
Source

PNWD-2023 HEDR

PNWD-2023 HEDR

\section{Data size}

134.4 Kb) (2 parameters $\times 3$ radionuclides $\times 7$ ages $\times 2$ sexes $\times 4$ organs $\times 100$ realizations $x$ 4 bytes)

\subsubsection{Reference Diet Library Data}

Representative diets for individuals of varying age, sex, and lifestyle will be provided to CIDER in the form of a library data fle. This flle will be used by an individual to choose one of the reference diets instead of specifying individualized consumption values. Because pre-natal infants do not eat solids, they have been eliminated from the age category. The reference diet library data size is derived from the following:

Parameter

Consumption rate of food product $\left(R_{p}\right)$

\section{Dependencies}

Foods, ages, sexes, lifestyles, seasons, realizations

\section{Data Size}

$346 \mathrm{~Kb}$ ( 1 parameter $\times 9$ foods $\times 6$ ages $\times 2$ sexes $\times 2$ lifestyles $\times 4$ seasons $\times 100$ realizations $\times 4$ bytes)
Source

Task 06 


\subsubsection{Reference Outdoor-Time Library Data}

A library file will provide representative estimates of time spent outdoors by age, sex. lifestyle, and season. Because pre-natal infants do not go outside, they have been eliminated from the age category. The reference outdoor-time library data size is dertved from the following:

Parameter

Source

Fraction of day spent outdoors $\left(f_{t i m e}\right)$ PNWD-2023 HEDR

Dependencies

Ages, sexes, lifestyles, seasons, realizations

\section{Data Size}

$38.4 \mathrm{~Kb} \quad(1$ parameter $\times 6$ ages $\times 2$ sexes $\times 2$ lifestyles $\times 4$ seasons $\times 100$ realizations $\times 4$ bytes)

\subsubsection{Other Input Data}

Several other data are needed to describe parameters necessary for calculating dose. These miscellaneous data are described here.

\subsubsection{Breathing-Rate Data}

Some data that are necessary for computing doses are the volume of air an individual breathes in a day. Because pre-natal infants do not breathe external air, they have been eliminated from the age category. The breathing rate data size is derived as follows:

Parameter

Source

Volume $\left(\mathrm{m}^{3}\right)$ of air breathed in a day (BR) PNWD-2023 HEDR

\section{Dependencles}

Ages, realizations

\section{Data Size}

\section{$2.4 \mathrm{~Kb} \quad$ (1 parameter $\times 6$ ages $\times 100$ realizations $\times 4$ bytes )}

\subsubsection{Air-Activity Data}

The air-activity data are necessary to calculate inhalation dose. They account for the difference in radionuclide concentration between indoor and outdoor air. The air-activity data size is dertved as follows: 
Indoor-to-outdoor air activity ratio $\left(\mathbf{R}_{\mathrm{lo}}\right)$

PNWD-2023 HEDR

\section{Dependenctes}

Realkations

Dxta Size

400 bytes (1 parameter $\times 100$ realizations $\times 4$ bytes)

\subsubsection{Radionuclide Data}

Radionuclide-specific data needed to calculate dose are provided here. The radionuclide data size is dertved as follows:

\section{Parameters}

External dose-reduction factor (shielding) in a building (Shl)

\section{Dependencies}

Radionuclides, realizations

\section{Data Size}

$1.2 \mathrm{~Kb} \quad(1$ parameter $\times 3$ radionuclides $\times 100$ realizations $\times 4$ bytes)

\subsubsection{Eood Storage-Time Data}

It is necessary to calculate the change in plant product concentrations from the time of harvest to the time of consumption. The estimates of storage time are provided here. Food consumption rates vary by month. The food storage-time data size is dertved from the following:

Parameter

Source

Time between harvest and ingestion of food plant type $p\left(t_{p}\right)$ PNWD-2023 HEDR

\section{Dependencies}

Foods, months, realizations

\section{Data Size}

$1.2 \mathrm{Mb} \quad$ (1 parameter $\times 9$ foods $\times 337$ months $\times 100$ realizations $\times 4$ bytes ) 


\subsubsection{DESCARTES-Produced Data}

All data concerning concentration of contaminanis in the environment are calculated by the DESCARTES computer code and saved to fles for input into the CIDER code.

\subsubsection{Environmental Data}

The environmental concentrations will be output from DESCARTES. There will be a preprocessor that will filter the data according to the deminimus dose level to significantly reduce storage requirements of the environmental data. Even with the filter, this file will be multiple gigabytes in size.

\subsubsection{Creamery Data}

To allow an individual to specify milk purchases from a specific creamery, the creamery milk concentrations produced in DESCARTES will be saved in a flle for input into CIDER. This data will also be filtered.

\subsubsection{Soll-Ratio Data}

To calculate the resuspension doses, CIDER uses the soll-ratio data obtained from the DESCARTES computer code.

\subsection{OUTPUT DATA}

Data will be output by CIDER to report doses for indtviduals and to create dose maps using a geographic information system (GIS). The data to be produced are described here.

\subsubsection{Individual-Dose Data}

The individual-dose data contain the dose by organ and pathway for the individual each year of the simulation. An effective dose is also reported for the individual. These data also contain the cumulative dose over multiple years for that individual.

\subsubsection{Map Data}

The map data are the annual dose over all nodes for a given individual. These data will be used to produce a GIS map of doses. 


\subsection{CIDER DATA-SIZE SUMMARY}

To compute the totals, all numbers have been rounded off to the nearest full integer. Zero indicates those data requiring less than half a megabyte. The total does not include DESCARTES generate' 1 data required to run CIDER.

Data Name

External dose factors

Internal dose factors

Reference diet

Reference outdoor time

Breathing rate

Air activity

Radionuclide

Eresh food storare time

Total
Data Ske (MT)L

0

0

0

0

0

0

0

1

1 


\subsection{AUXILIARY}

\subsection{LOCATION TRANSLATION DATA}

The DESCARTES and CIDER codes will operate on a node basis. Some of the locationdependent data needed by the codes are provided by county or census division. The data must be translated into the node level. A master fle will be developed independent of the DESCARTES and CIDER codes to translate any fles that are not on a node basis. This flle will contain the node identification, the node coordinates ( $x$ - $y$ location of the node centroid), the dimensions of the node. the census division containing the node, and the county containing the node. The location translation data size is derived from the following:

Parameters

Node identification

Node coordinates ( 2 values)

Node dimensions ( 2 values)

Census division identification

County identification

Dependencies

Nodes

\section{Datasize}

$58.5 \mathrm{~Kb} \quad(7$ parameters $\times 2091$ nodes $\times 4$ bytes)

\subsection{DATABASE FILTER DATA}

The data will be filtered before and after the environmental accumulation calculations to eliminate nodes where no contaminants were found. Nodes can exit and re-enter the calculations. For the data-size estimates, however, it is assumed that each node enters and exdts once.

Before data are put into the DESCARTES code. nodes will be eliminated based on the air concentration data. Before data are put into the CIDER code. nodes will be eliminated based on a screening estimate of dose. This will significantly reduce the amount of computation required by the CIDER code. 


\subsubsection{Alr-Concentration Fulter Data}

An active air node list will be produced by the pre-processor which interprets the air data for use by DESCARTES. This will ensure that only nodes with an air concentration above the deminimus level will be included in any given month. The database filter data size is derived from the following:

\section{Parameters}

Node identification

Tume on

Time off

\section{Dependencies}

Nodes, months

\section{Data Size}

$8.5 \mathrm{Mb} \quad$ (3 parameters $\times 2091$ nodes $\times 337$ months $\times 4$ bytes)

\section{Source}

Pre-processor

Pre-processor

Pre-processor

\subsubsection{Dose-Level Filter Data}

An active dose node list will be produced by the processor which interprets the DESCARTES database for use by CIDER. This will ensure that only nodes with representative doses above a deminimus level will be included in any month. The dose-level filter data size is derived from the following:

\section{Parameters}

Node Identification

Time on

Time off

\section{Dependencies}

Nodes, months

Datasize

$8.5 \mathrm{Mb} \quad$ (3 parameters $\times 2091$ nodes $\times 337$ months $x 4$ bytes)

\section{Source}

Pre-processor

Pre-processor

Pre-processor 


\subsection{AUXILIARY DATA SUMMARY}

To compute the totals all numbers have been rounded off to the nearest full integer. Zero indicates those data requiring less than half a megabyte.

\section{Data Name}

Location translation

Alr-concentration filter

Dose-lever fulter

Total
Data Size (Mb)

0

9

9

18 


\subsection{REFERENCES}

Beck, D. M., R. F. Darwin, A. R. Erikson, and R. L. Eckert. 1992. Mulk Cow Feed Intake and Mulk Production and Distribution Estimates for Phase I. PNL-7227 HEDR, Pacific Northwest Laboratory, Richland, Washington.

Marsh, T. L., D. M. Anderson, W. T. Farris, T. A. Ikenberry, B. A. Napier, and G. L. Wilbert. 1992. Commercial Production and Distribution of Fresh Fruits and Vegetables: A Scoping Study on the Importance of Produce Pathways to Dose. PNWD-2022 HEDR, Battelle Pacific Northwest Laboratorles, Richland, Washington.

Napier, B.A. 1991. Selection of Dominant Radionuclides for Phase I of the Hanford Envtronmental Dose Reconstruction Project. PNL-7231 HEDR, Pacific Northwest Laboratory, Richland. Washington.

Snyder, S. F., W. T. Farris, B. A. Napier, T. A. Ikenberry, and R. O. Gilbert. 1992. Parameters Used in the Envtronmental Pathways (DESCARTES) and Radiological Dose (CIDER) Modules of the Hanford Envtrormental Dose Reconstruction Integrated Codes (HEDRIC) for the Air Pathway. PNWD-2023 HEDR, Battelle Pacific Northwest Laboratories, Richland, Washington. 

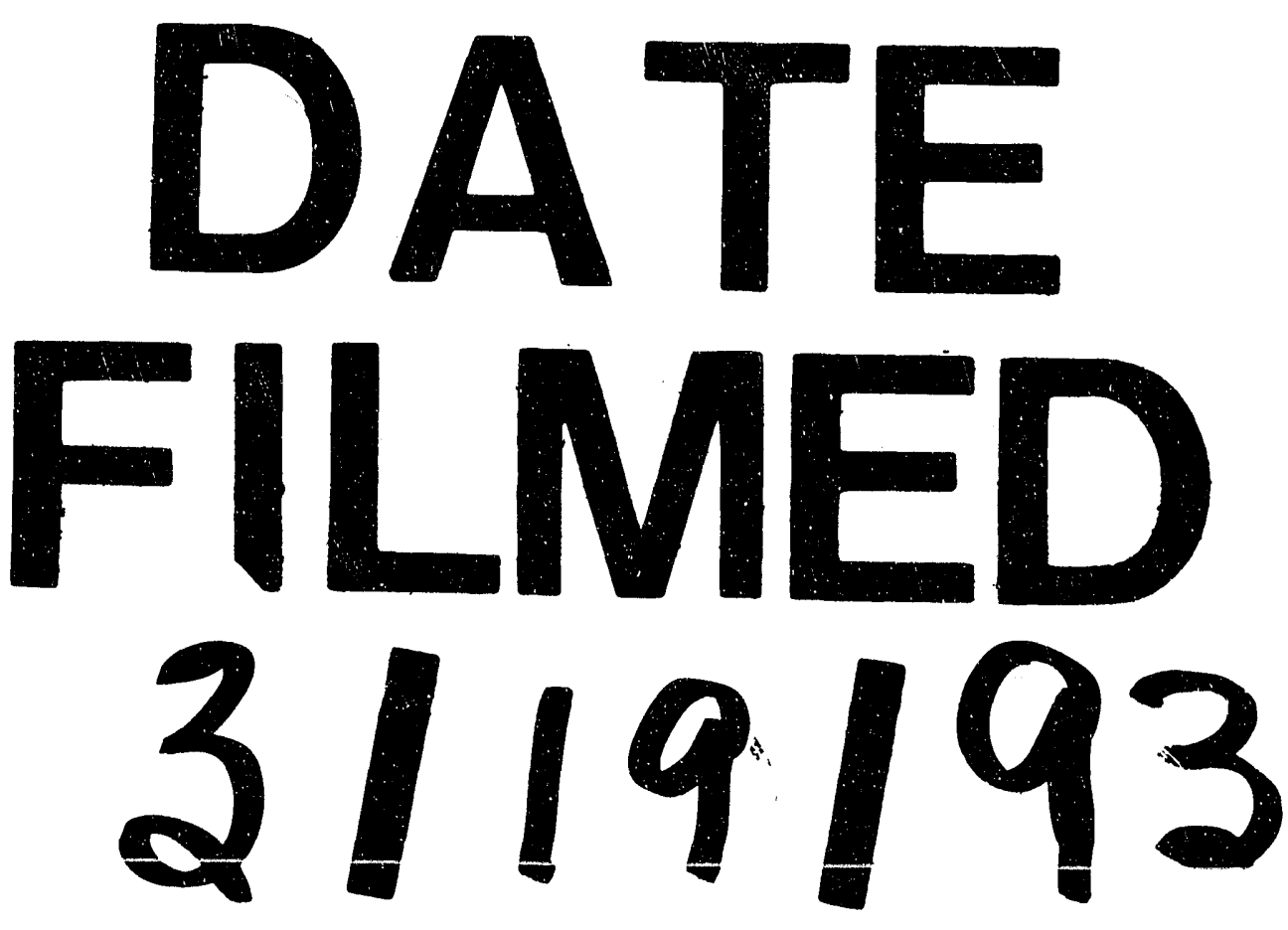
